\title{
Commentary
}

\section{A closer look at the weekend effect and COVID-19 mortalities}

\author{
Hany Aly* \\ Department of Neonatology, Cleveland Clinic Children's Hospital, Cleveland, OH, USA
}

Received 20 October 2020

Accepted 24 October 2020

The severe acute respiratory syndrome coronavirus clade 2 (SARS-CoV-2), which causes the disease COVID-19, is highly pathogenic and continues to spread worldwide with over $38,450,131$ total confirmed cases and 1,092,263 deaths, in 216 countries/regions [1]. While more than 24 million infected individuals have recovered from the coronavirus infection, in the United States (U.S.) alone, there have been more than 220,989 deaths related to COVID-19 [2].

COVID-19 can affect anyone and the spectrum of symptomatic infection ranges from mild to critical, depending on the individual's comorbidities and other underlying conditions [3]. The disease is generally characterized by pneumonia, fever, cough, and occasional diarrhea, but symptoms can vary among those infected [4]. It is true that not all patients with COVID-19 need hospitalization, however, patients whose clinical presentation warrants physician management will require hospital admission.

In healthcare, the pervasive phenomenon known as the 'weekend effect' suggests that patients admitted to hospitals on Saturday and Sunday have an increased risk of death [5]. Although this is a controversial area, the majority opinion is that the weekend effect is deleterious to patient care. While the cause of

\footnotetext{
*Address for correspondence: Hany Aly, MD, MSHS, Department of Neonatology, Cleveland Clinic Children's Hospital, Cleveland, OH 44195. Tel.: +1 216444 2568; Fax: +1 216444 7625; E-mail: alyh@ccf.org.
}

this effect is unclear, the weekend effect on mortality is apparent across a range of disease presentations [5].

A 2017 meta-analyses of 97 studies showed that patients admitted on the weekends had a significantly higher overall mortality (relative risk, 1.19; 95\% confidence interval, 1.14-1.23) [6]. With regard to subgroup analyses, patients admitted on the weekends consistently had higher mortality than those admitted during the week, regardless of the levels of weekend/weekday differences in staffing, procedure rates and delays, and illness severity [6]. Contradictory studies such as that by Freemantle et al., showed that the likelihood of death by all causes is less on a weekend day than on a mid-week day [7]. Research continues on this matter to better understand the reasons and implications of the weekend effect and how caregivers may address them.

To determine the extent to which the weekend effect is associated with COVID-19 mortalities, we recently surveyed COVID-19 deaths within the U.S. using data presented by the Worldometer [2]. We specifically assessed the difference between deaths that occurred Monday-Friday (weekdays) versus those that occurred on Saturday and Sunday (weekend) from March through October. Examination of COVID-19 associated deaths in the U.S. showed significantly less deaths on Saturday and Sunday, compared to deaths on weekdays $(Z=3.527$, $p=0.0004$ ) (Fig. 1). While we weren't able to determine factors such as illness severity at time of admission and staffing level differences during the 


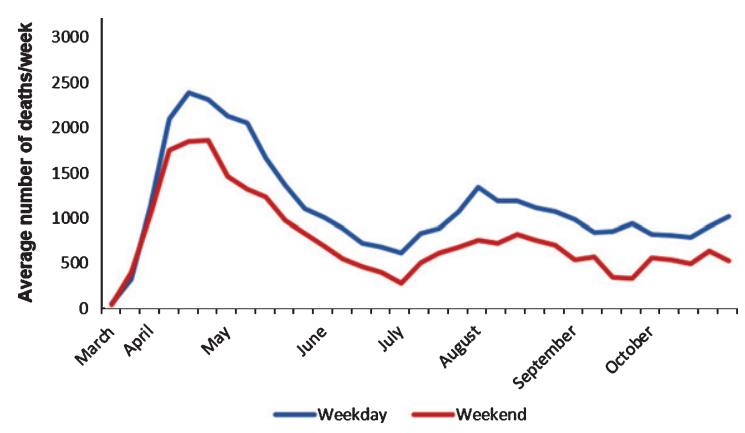

Fig. 1. Average weekday and weekend deaths associated with COVID-19 in the U.S. Significantly less COVID-19 associated deaths occurred in the U.S. on Saturday and Sunday (weekend), compared to deaths on weekdays $(Z=3.527, p=0.0004)$.

week versus on the weekend, this is still an interesting finding and something that should be investigated further. If decreased COVID-19 mortality was related to reporting delays during weekends, we should have noticed surges in mortality on Mondays. However, this is not true, as mortality on Mondays was not any higher than other days of the week. Interestingly, the "weekend effect" we report for COVID-19 in the US, does not exist in other countries such Germany, Italy, Iran and Turkey.

During a global pandemic, such as what we are experiencing with COVID-19, taking a closer look at mortality rates and understanding the reasons for fluctuations allows caregivers to assess their practices to provide the best outcomes for patients. Further studies, with detailed clinical data are urgently needed to investigate the drivers of and causes for the risk of death on weekdays/weekends from COVID-19.

\section{References}

[1] Dong E, Du H, Gardner L. An interactive web-based dashboard to track COVID-19 in real time. Lancet Infect Dis. 2020;20(5):533-4.

[2] Worldometer. COVID-19 Coronavirus pandemic. https:// www.worldometers.info/coronavirus/ (Accessed on September 29, 2020).

[3] Centers for Disease Control and Prevention. People who are at higher risk for severe illness. https://www.cdc.gov/ coronavirus/2019-ncov/need-extra-precautions/people-athigher-risk.html (Accessed on August 26, 2020).

[4] Lu R, Zhao X, Li J, Niu P, Yang B, Wu H, et al. Genomic characterization and epidemiology of 2019 novel coronavirus: Implications for virus origins and receptor binding. Lancet. 2020;395(10224):565-74.

[5] Mathew A, Fyyaz SA, Carter PR, Potluri R. The enigma of the weekend effect. J Thorac Dis. 2018;10(1):102-5.

[6] Pauls LA, Johnson-Paben R, McGready J, Murphy J, Pronovost PJ, Wu CL. The weekend effect in hospitalized patients: A meta-analysis. J Hosp Med. 2017;12(9):760-6.

[7] Freemantle N, Richardson M, Wood J, Ray D, Khosla S, Shahian D, et al. Weekend hospitalization and additional risk of death: An analysis of inpatient data. J R Soc Med. 2012; 105(2):74-84. 